\title{
On the absorption of radiant heat by gases and vapours
}

\section{Lecher \& Pernter}

To cite this article: MM. Lecher \& Pernter (1880) On the absorption of radiant heat by gases and vapours, Philosophical Magazine Series 5, 10:61, 210-212, DOI: $10.1080 / 14786448008626919$

To link to this article: http://dx.doi.org/10.1080/14786448008626919

曲 Published online: 08 May 2009.

Submit your article to this journal $[\pi$

Џ Article views: 2

Q View related articles $\asymp$ 
are disposed symmetrically about this line as an axis. These experiments serve to explain the singular circumstance, that when complementary colours are produced by the aid of polarized light, it is difficult or impossible to oblain a red which is entirely free from a purplish hue, a quantity of white light being always necessarily mingled with the coloured light. In the case of the red, orange, yellow, ultramarine, and purple disks, I succeeded in measuring the amount of violet light which different proportions of the white disk virtually added to the mixture, and found that it was not directly proportional to the amount of white light added, but increased in a slower ratio, which at present has not been accurately determined.

For the explanation of the above-mentioned phenomena, Brücke's suggestion that white light contains a certain amount of unneutralized red light is evidently inapplicable, since the effects are such as would be produced by adding a quantity not of red but of violet light; and for the present I am not disposed to assume that white light contains an excess of violet light. The explanation offered by Aubert does not undertake to account for the changes produced in colours other than ultramarine, and even in this case seems to me arbitrary; neither have I succeeded in framing any explanation in accordance with the theory of Young and Helmholtz which seems plausiblo.-Silliman's American Joumal, August 1880.

\section{ON THE ABSORPTION OF RADIANT HEAT BY GASES AND VAPOURS,} BY MM. LECHER AND PERNTER.

The authors discuss the different methods previously employed in similar investigations, and in particular the arrangements employed by Tyndall, and the vapour-adhesion to which they are liable, and show from numbers given by Tyndall himself how important a source of error this may become. Tyndall's results often differ by 30 per cent., according as the whole or only half of the experimental tube was polished.

There is scarcely any other reason to be found for this difference than vapour-adhesion. That a condensation of vapour along the walls of the tube took place may be shown directly by comparing Tyndall's observations in which the vapour-pressure was measured directly, with those in which the experimental tube was filled with yapour by being repeatedly placed in communication with a flask containing the corresponding vapour in a state of saturation. We can conclude from the absorption observed what the pressure must be in the flask. We find thus for benzol-vapour, for example, a tension of two atmospheres, which corresponds to a temperature of $100^{\circ} \mathrm{C}$. But as the temperature in fact was $11^{\circ} \mathrm{C}$., the excess of rapour must have resulted from precipitated liquid on the sides of the tube.

The anthors were led by these considerations, and by experience obtained from numerous failures, to adopt finally an orrangement in which the thermopile and source of heat were placed in the same ressel. The influence of currents of air is rendered imperceptiblo 
by bringing the radiating surface suddenly to $100^{\circ} \mathrm{C}$. by a stream of boiling water applied exteriorly.

Of results must be mentioned, in the first place, that the absorption of radiant heat by aqueous vapour, in opposition to Tyndall's results, is found to be excessively small. The authors show that the contradiction between this result and certain meteorological observations is only apparent.

The experiments made by Violle on Mont Blanc show that one metre of the air at the place of observation absorbed only 0.007 per cent. of the total radiation. If account is taken of the hygrometric condition of the air, and the difference in wave-length of the heat experimented upon, we arrive at the conclusion that, taking Violle's observations as correct, it would require a layer of 300 metres of saturated aqueous vapour at $12^{\circ}$ to produce the absorption of radiant heat which Tyndall finds for a length of 1.22 metre. By this simple calculation, as well as by the experimental results obtained, we may regard Magnus's view as established-that aqueous vapour exerts hardly any absorption on radiant heat.

The rest of the numbers obtained for gases agree fairly well with those given by Tyndall (which of course is not the case with the vapours examined). At atmospheric pressure the intensity of the radiation through a column of 310 millims. length (the intensity of the incident radiation being 100) is for

$$
\begin{array}{lll}
\text { Air } \ldots \ldots \ldots \ldots & \ldots \ldots \ldots & 99 \cdot 8 \\
\text { Carbonic oxide } & \ldots \ldots \ldots & 93 \cdot 3 \\
\text { Carbon dioxide } \ldots \ldots \ldots & 92 \cdot 3 \\
\text { Ethylene } \ldots \ldots \ldots \ldots \ldots & \mathbf{5 1} \cdot 8
\end{array}
$$

It appears, further, that there is no simple relation between the absorption and the pressure of the substances experimented upon; and the absorption, even for the radiation from a source of heat at $100^{\circ}$, is a selective one. Hence too much importance is not to be attributed to the relation which is pointed out in the present paper between absorption and chemical eomposition, which is as follows. After the absorption for vapours at equal pressure (that is, for an equal number of molecules) had been found by a graphical method, it was seen that the absorption-coeffieients for radiation at $100^{\circ} \mathrm{C}$. of the substances examined which belonged to the fatty series might be arranged somewhat as follows:-

I. Methyl-alcohol, formic aeid, carbon monoxide, carbon dioxide, chloroform.

II. Ethyl alcohol (acetic acid), ethyl ether, ethylene.

III. Butyl alcohol.

IV. Amyl alcohol.

The absorption is nearly the same for the substances in each series, but rises rapidly as the percentage of carbon increases.

It seems to be otherwise with bodies belonging to other groups. Thus, for example, benzol, notwithstanding its 6-carbon atom, possesses a somewhat small absorption-coefficient. Whether this is a consequence of the different linking of these carbon atoms and the consequent modification of the mode of vibration, can only be de- 
cided by a spectroscopic examination of the absorption.-Berichte der laiserlichen Akademie der Wissenschaften in Wien, 1880, XVII. pp. 135-138.

SPECTROSCOPIC RESEARCHES. BY DR. G. L. CIAMICIAN.

The author has obtained the following results by the study of twenty elements :-

I. Carbon has two spectra, one of the first and one of the second order, in accordance with the general rule that each element possesses two spectra.

UI. Amongst carbon-compounds, only cyanogen, carbon-monoxide, and acetylene have special spectra.

III. The spectra of the radicals cyanogen and carbonyl have a simple relation to the spectra of the first order of their components. The most refrangible end of the carbonic-oxide and cyanogeu spectra is homologous with that of the carbon spectrum of the first order. On the other hand, the less refrangible half of the cyanogen spectrum is to be compared with that of the nitrogen spectrum of the first order.

IV. The spectra of the second order of carbon, boron, silicon, and aluminium are homologous. It is to be remarked that the less refrangible end of the spectra of silicon and aluminium has nothing corresponding to it in the spectra of carbon and boron, and is comparable with the less refrangible portions of the spectra of the elements of the oxygen group. Boron, silicon, and aluminium have also spectra of the first order which correspond to the spectrum of carbon of the first order.

V. The spectra of the first and second order of carbon and of magnesium are completely homologous.

VI. The more refrangible half of the homologous spectra of barium, strontium, and calcium is homologous with the magnesium spectrum.

VII. The spectra of the elements oxygen, sulphur, selenium, and tellurium are completely homologous amongst themselves, both as regards the more refrangible and the less refrangible halves.

VIII. The spectra of phosphorus, arsenic, and antimony are to be compared with the spectrum of nitrogen in the red portions; and in like manner only the less refrangible portions of the spectra of the halogens are homologous with the spectrum of fluorine.

IX. The less refrangible end of the spectra of silicon, aluminium, calcium, strontium, and barium is homologous with that of the spectra of the elements of the oxygen group; and those elements are more nearly comparable which form a horizontal line in Mendelejeff's table, e.g. sulphur, silicon, aluminium, calcium, selenium, strontium and tellurium, barium.

$\mathrm{X}$. The more refrangible end of the spectra of chlorine, bromine, iodine and phosphorus, arsenic and antimony, is homologous with the more refrangible part of the spectra of the elements of the oxygen group; the elements sulphur, chlorine, phosphorus, bromine, arsenic and tellurium, iodine, antimony are most nearly comparable.

From these relations of homology of the elements, and on 